\title{
Allergic Bronchopulmonary Aspergillosis in Asthma and Cystic Fibrosis
}

\author{
Alan P. Knutsen ${ }^{1,2}$ and Raymond G. Slavin ${ }^{2,3}$ \\ ${ }^{1}$ Department of Pediatrics, Saint Louis University, 1465 South Grand Boulevard, St. Louis, MO 63104, USA \\ ${ }^{2}$ Division of Infection Diseases, Allergy and Immunology, Saint Louis University, 1465 South Grand Boulevard, St. Louis, \\ MO 63104, USA \\ ${ }^{3}$ Department of Internal Medicine, Saint Louis University, 1465 South Grand Boulevard, St. Louis, MO 63104, USA
}

Correspondence should be addressed to Alan P. Knutsen, knutsenm@slu.edu

Received 13 December 2010; Accepted 8 February 2011

Academic Editor: K. Blaser

Copyright ( $\odot 2011$ A. P. Knutsen and R. G. Slavin. This is an open access article distributed under the Creative Commons Attribution License, which permits unrestricted use, distribution, and reproduction in any medium, provided the original work is properly cited.

\begin{abstract}
Allergic bronchopulmonary aspergillosis (ABPA) is a Th2 hypersensitivity lung disease in response to Aspergillus fumigatus that affects asthmatic and cystic fibrosis (CF) patients. Sensitization to A. fumigatus is common in both atopic asthmatic and CF patients, yet only 1-2\% of asthmatic and 7-9\% of CF patients develop ABPA. ABPA is characterized by wheezing and pulmonary infiltrates which may lead to pulmonary fibrosis and/or bronchiectasis. The inflammatory response is characterized by Th2 responses to Aspergillus allergens, increased serum IgE and eosinophilia. A number of genetic risks have recently been identified in the development of ABPA. These include HLA-DR and HLA-DQ, IL-4 receptor alpha chain (IL-4RA) polymorphisms, IL-10-1082GA promoter polymorphisms, surfactant protein A2 (SP-A2) polymorphisms, and cystic fibrosis transmembrane conductance regulator gene (CFTR) mutations. The studies indicate that ABPA patients are genetically at risk to develop skewed and heightened Th2 responses to A. fumigatus antigens. These genetic risk studies and their consequences of elevated biologic markers may aid in identifying asthmatic and CF patients who are at risk to the development of ABPA. Furthermore, these studies suggest that immune modulation with medications such as anti-IgE, anti-IL-4 and/or IL-13 monoclonal antibodies may be helpful in the treatment of ABPA.
\end{abstract}

\section{Introduction}

Allergic bronchopulmonary aspergillosis (ABPA) is a hypersensitivity lung disease due to bronchial colonization by Aspergillus fumigatus that occurs in susceptible patients with asthma and cystic fibrosis (CF). The first published description of ABPA as an entity came from the United Kingdom in 1952 [1], while the first cases in the United States were reported a decade later $[2,3]$. ABPA affects approximately $1-2 \%$ of asthmatic patients and $7-9 \%$ of CF patients [4-6]. If unrecognized or poorly treated, ABPA leads to airway destruction, bronchiectasis, and/or pulmonary fibrosis, resulting in significant morbidity and mortality.

\section{Biology of Aspergillus fumigatus}

A number of fungi may lead to allergic bronchopulmonary mycoses (ABPM), but the genus Aspergillus contains the predominant organisms causing these pulmonary disorders; Aspergillus fumigatus is the species most commonly associated with ABPM. It is a ubiquitous, saprophytic mold found in both outdoor and indoor air, in potting soil, crawl spaces, compost piles, mulches, freshly cut grass, decaying vegetation, and sewage treatment facilities $[7,8]$. A. fumigatus is found worldwide including the United States, where it is especially prevalent in the Midwest and East coast. Aspergillus spores are common indoors and outdoors. Aspergillus species are thermotolerant growing at $15^{\circ}$ to $53^{\circ} \mathrm{C}$ temperatures 
and particularly grows well at $37^{\circ}$ to $40^{\circ} \mathrm{C}$ which allows for sporulation in human bronchi. Septated hyphae of A. fumigatus are 7 to $10 \mu \mathrm{m}$ in diameter with branching at $45^{\circ}$ angles. Hyphae may be demonstrated in sputum, mucus plugs or sinus debris with Gomori methenamine-silver or periodic acid-Schiff stains.

\section{Aspergillus-Associated Pulmonary Diseases}

A. fumigatus is responsible for a variety of pulmonary diseases depending on the individual's genetic status and immunologic responses to Aspergillus antigens. These include:

(1) atopic asthma,

(2) invasive aspergillosis,

(3) aspergilloma (mycetoma),

(4) hypersensitivity pneumonitis,

(5) asthma,

(6) allergic bronchopulmonary aspergillosis

(a) in asthma and

(b) in cystic fibrosis.

3.1. Atopic Asthma. Asthmatic patients may develop IgE sensitivity to molds including $A$. fumigatus. A number of investigators have reported that onset, persistence, and severity of asthma are associated with sensitivity to fungus, especially Cladosporium and Alternaria [9-15]. Recently, David Denning's group coined the term severe asthma associated with fungal sensitivity (SAFS) [16]. In their studies, sensitivity to A. fumigatus was the most common fungus causing sensitization. Furthermore, treatment with the antifungal agent itraconazole improved their asthma. Another series of studies by Andrew Wardlaw's group also demonstrated that sensitivity to A. fumigatus was associated with severe asthma [17]. In those studies, A. fumigatus could be cultured from sputum specimens. FEV-1 was decreased and total IgE levels were elevated. The asthmatic patients in both Denning's and Wardlaw's studies did not fulfill criteria for ABPA. Colonization with A. fumigatus and development of ABPA also occurs in cystic fibrosis patients [18]. A number of investigators have reported that colonization with $A$. fumigatus in CF is associated with decreased FEV-1 and more rapid pulmonary function decline even when not diagnosed as ABPA. These studies suggest that there is a spectrum of pulmonary disease states due to A. fumigatus sensitization in asthmatic and CF patients from severe asthma to ABPA.

3.2. Invasive Aspergillosis. Invasive aspergillosis occurs in individuals who have an iatrogenic or congenital immunodeficiency. The congenital immunodeficiencies are neutrophil defects, such as chronic granulomatous disease (CGD) and leukocyte adhesion defects (LAD). The iatrogenic defects are secondary to chemotherapy that results in neutropenia. In invasive aspergillosis, A. fumigatus invades the bronchial epithelia resulting in pneumonia, tracheobronchitis, pulmonary diseases, and pleural effusions. A. fumigatus may result in osteomyelitis and central nervous system infections. Treatment is with antifungal medications, such as itraconazole, voriconazole, or posaconazole.

3.3. Aspergilloma. Aspergilloma or mycetoma occurs in individuals with pre-existing pulmonary diseases, such as bronchocentric carcinoma, cavitary tuberculosis, pulmonary histoplasmosis, cystic fibrosis, sarcoidosis, and bronchiectasis. Aspergillus spores germinate in these structures forming a tangled mass of hyphae, termed a fungus ball. Hemoptysis is a common symptom. IgG anti-Aspergillus antibodies are usually extremely elevated, but specific IgE anti-Aspergillus antibodies are usually not detectable. Treatment consists of antifungal medication and surgical excision of the cavity.

3.4. Hypersensitivity Pneumonitis. Hypersensitivity pneumonitis (HP) or extrinsic allergic alveolitis is caused by a variety of antigens, including bird droppings (Pigeon Breeder's disease), murine urine proteins (Laboratory Worker's lung), thermophilic moldy hay (Farmer's lung), Aspergillus clavatus moldy brewery barley (Malt Worker's disease), and others. The symptoms in the acute stage include fever, nonproductive cough, and dyspnea. In the subacute stage, the symptoms are malaise, low-grade fevers, nonproductive cough, and dyspnea. In the chronic stage, the symptoms are chronic cough, dyspnea, fatigue, anorexia, and weight loss. Chest radiograph displays micronodular pulmonary infiltrates, ground-glass opacities, or diffuse infiltrates. The immunologic response to the antigen is a Th1 cell-mediated reaction. IgG-specific antibodies are typically extremely elevated. Treatment is removal of the antigen source and corticosteroids.

\section{Diagnosis and Staging of ABPA}

The diagnosis of ABPA is based on clinical and immunologic reactivity to A. fumigatus. The minimal criteria required for the diagnosis of ABPA are (1) asthma or cystic fibrosis with deterioration of lung function, for example, wheezing, (2) immediate Aspergillus skin test reactivity, (3) total serum IgE $\geq 1000 \mathrm{IU} / \mathrm{mL}$, (4) elevated Aspergillus specific IgE and IgG antibodies, and (5) chest radiographic infiltrates (Table 1). Additional criteria may include peripheral blood eosinophilia, Aspergillus serum precipitating antibodies, central bronchiectasis, and Aspergillus containing mucus plug production [19-23]. The designation of ABPA-seropositive (ABPA-S) may be used to classify asthmatic patients who meet the required criteria but lack the proximal or central bronchiectasis (ABPA-CB). The clinician should note that the development of ABPA is not dependent on asthma severity. The diagnosis of ABPA in CF is more complicated and disagreement exists in the literature regarding the diagnostic criteria. The difficulty lies in the fact that the usual criteria for ABPA and the common signs and symptoms of CF overlap. The most recent Cystic Fibrosis Foundation Consensus Conference proposed the following diagnostic criteria: (1) acute or subacute pulmonary deterioration not attributable to another etiology, (2) total serum $\operatorname{IgE}>1000 \mathrm{IU} / \mathrm{mL}$, 
TABLE 1: Criteria for diagnosis of allergic bronchopulmonary aspergillosis in asthma.

(1) Asthma

(2) Chest radiographic infiltrate(s)

(3) Allergy prick skin reactivity to A. fumigatus

(4) Elevated total serum IgE level $\geq 1000 \mathrm{IU} / \mathrm{mL}$. Some groups recommend $\mathrm{IgE} \geq 1000 \mathrm{ng} / \mathrm{mL}(416 \mathrm{IU} / \mathrm{mL})$

(5) Precipitating IgG antibodies to A. fumigatus

(6) Peripheral blood eosinophilia

(7) Elevated serum specific IgE anti-A. fumiatus antibodies greater than twice non-ABPA IgE A. fumigatus-positive asthmatic serum pool

(8) Elevated serum specific IgG anti-A. fumiatus antibodies

(9) Central bronchiectasis

(i) Criteria 1-9, ABPA-central bronchiectasis, ABPA-CB.

(ii) Criteria 1-8, ABPA-seropositive, ABPA-S.

(3) immediate cutaneous reactivity to Aspergillus or in vitro specific IgE antibodies to Aspergillus, and (4) one of the following: Aspergillus serum precipitins, elevated specific IgG anti-Aspergillus antibodies, or new or recent chest radiographic or chest $\mathrm{CT}$ abnormalities that have not cleared with antibiotics and chest physiotherapy (Table 2) [23].

4.1. Clinical Staging. The spectrum of ABPA varies widely, from individuals with mild asthma and occasional episodes of pulmonary eosinophilia with no long-term sequelae, to patients with fibrosis, honey-comb lung, and respiratory failure. Patterson and colleagues [22, 23] have suggested a clinical classification with five clinical stages of ABPA in asthmatics (Table 3). Stage I is the initial acute stage of ABPA with many of the typical features of the disease. In stage II, the disease goes into remission; the infiltrates clear, symptoms are reduced, and the serum IgE value will decline by up to $35 \%$ within 6 weeks. Stage III is an exacerbation associated with the recurrence of the initial symptoms and a twofold increase in serum IgE levels. Stage IV is reached when patients need continuous corticosteroids either to control their asthma or to prevent a recurrence of ABPA. Stage V is the fibrotic stage, which is present when there is severe upper lobe fibrosis present on the chest radiograph, and it may be associated with honeycombing. The stage $\mathrm{V}$ lesions may not respond to corticosteroids, although steroids are often necessary to maintain a bronchodilator response, and severe wheezing may develop if steroids are discontinued. Pulmonary fibrosis is an advanced complication that can lead to pulmonary hypertension and cor pulmonale.

4.2. Radiographic Findings. There are several characteristic radiographic abnormalities associated with ABPA [19-23]. The most common lesion is a large, homogeneous shadow in one of the upper lobes with no change in volume. The shadow may be triangular, lobar, or patchy, and it frequently moves to another site. "Tram-line" shadows are fine parallel lines radiating from the hila that represent inflammation
TABle 2: Criteria for diagnosis of allergic bronchopulmonary aspergillosis in cystic fibrosis.

\section{Classic Diagnostic Criteria}

(i) Acute or subacute clinical deterioration not attributable to another etiology

(ii) Total serum IgE concentration greater than $1000 \mathrm{IU} / \mathrm{mL}$ unless patient is receiving corticosteroid therapy

(iii) Immediate cutaneous reactivity to Aspergillus fumigatus while the patient is not being treated with antihistamines or in vitro presence of serum IgE antibody to A. fumigatus

(iv) Precipitating antibodies or serum IgG antibody to $A$. fumigatus

(v) New or recent abnormalities on chest radiography or chest CT that have not cleared with antibiotics and standard physiotherapy

Minimal Diagnostic Criteria

(i) Acute or subacute clinical deterioration not attributable to another etiology

(ii) Total serum IgE concentration greater than $500 \mathrm{IU} / \mathrm{mL}$ unless patient is receiving corticosteroid therapy. If ABPA is suspected and the total level of 200 to $500 \mathrm{IU} / \mathrm{mL}$, repeat testing in 1 to 3 months is recommended. If patient is taking steroids, repeat when steroid treatment is discontinued.

(iii) Immediate cutaneous reactivity to Aspergillus fumigatus while the patient is not being treated with antihistamines or in vitro presence of serum IgE antibody to A. fumigatus

(iv) One of the following: (a) precipitins to A. fumigatus or in vitro documentation of IgG antibody to A. fumigates, or (b) new or recent abnormalities on chest radiography or chest CT that have not cleared with antibiotics and standard physiotherapy

of airway walls. Mucoid impaction causes toothpaste shadows or gloved-finger shadows. Adult patients have been reported with normal chest radiographs so radiographic abnormalities are not invariably present. In these individuals, cylindrical bronchiectasis was demonstrated by tomography or CT scan. However, central bronchiectasis is a common complication and finding in all CF patients.

4.3. Laboratory Investigations. Laboratory tests that support the diagnosis of ABPA are those that demonstrate allergy to the $A$. fumigatus, such as elevated specific IgE anti-Aspergillus antibodies and positive Aspergillus precipitins [19-23]. The precipitins are only weakly positive compared with the strong reactions seen in patients with mycetomas. Culture of $A$. fumigatus from the sputum is only a secondary criterion for the diagnosis of ABPA, because a large proportion of individuals with CF without ABPA have Aspergillus on sputum cultures. Some normal individuals and many individuals with lung diseases have small numbers of spores in their sputum; these are probably present because of passive inhalation. The presence of hyphae is more specific, and the presence of eosinophils in association with hyphal elements is suggestive of the diagnosis. The presence of eosinophilia in sputum or blood is suggestive of ABPA in asthmatics and is a primary diagnostic criterion. The peripheral blood eosinophil count is usually greater than $1000 / \mathrm{mm}^{3}$, and values greater than $3000 / \mathrm{mm}^{3}$ are common. As denoted in Table 2, 
TABLE 3: Staging of allergic bronchopulmonary aspergillosis in asthmatics.

\begin{tabular}{lcccccc}
\hline Stage & IgE level & Precipitins & Eosinophilia & IgE-Af & IgG-Af & Pulmonary infiltrates \\
\hline (I) Acute & +++ & + & + & + & & + \\
(II) Remission & + & \pm & - & \pm & \pm & + \\
(III) Exacerbation & +++ & + & + & + & + & - \\
(IV) Corticosteroid dependent & ++ & \pm & \pm & \pm & \pm & + \\
(V) Fibrotic & + & \pm & - & \pm & \pm & - \\
\hline
\end{tabular}

eosinophilia is not a diagnostic criteria of ABPA in CF patients. In the authors' experience, eosinophilia is an uncommon finding in CF ABPA patients.

An increased total serum IgE level is very characteristic of ABPA, and values may reach as high as $30,000 \mathrm{IU} / \mathrm{mL}$. Usually, the level is greater than $1000 \mathrm{IU} / \mathrm{mL}$. Much of the IgE is not specific to Aspergillus but is the result of polyclonal B-cell activation. The IgE level is a very useful marker of disease activity, and it can be used to follow outpatients for "flares". The simple skin-prick test is a useful screening test, as ABPA is very unlikely in patients with a negative reaction. A dual-reaction skin test with an immediate (1015 minutes) and a late (4-8 hours) reaction occurs in one third of patients with ABPA. Alternatively, serum may be measured for the presence of specific IgE and IgG antibodies. Patients with Aspergillus-sensitive asthma will generally have elevated Aspergillus-specific IgE antibodies, but patients with ABPA will have much higher Aspergillusspecific IgE levels. Hemmann et al. [24] reported that ABPA and Aspergillus-sensitive patients have elevated IgE antibodies to recombinant Aspergillus Asp f1, Asp f3, Asp f4, and Asp f6 allergens, and that IgE levels to Asp f4 and Asp f6 is highly specific for ABPA in CF patients.

Differentiating between a bacterial flare versus an ABPA flare in CF patients may be difficult. A useful serum biologic marker may be thymus and activation-regulated chemokine (TARC) or CCL17. Latzin et al. [25] and Hartl et al. [26] reported that TARC was elevated in CF patients with ABPA and was further elevated during acute flares of ABPA. TARC is a chemokine whose ligand is CCR4 receptor on $\mathrm{CD} 4^{+} \mathrm{Th} 2$ cells.

In ABPA immunoelectrophoresis generally shows one to three precipitin lines, often to only one extract [19-23]. Patients with aspergilloma will have multiple precipitin lines to all antigen extracts. Extracts of A. fumigatus contain a complex mixture of proteins that are mainly derived from the hyphae. Antigenic composition varies between batches according to the culture conditions, even within the same laboratory. There is, therefore, a lack of standardization that makes it difficult to compare results between laboratories. However, there has been some success with purification of the major antigenic components that may lead eventually to improved diagnosis.

\section{Pulmonary Pathology of ABPA}

The gross pathology of ABPA demonstrates cylindrical bronchiectasis of the central airways, particularly those to the upper lobes [19-23]. These airways may be occluded by "mucoid impaction," a condition in which large airways are occluded by impacted mucus and hyphae. Airway occlusion may lead to atelectasis of a segment or lobe and, if the atelectasis is long-standing, saccular bronchiectasis may result. Typically, ABPA is worse in the upper lobes than in the lower lobes. Microscopic examination of the airways shows infiltration of the airway wall with eosinophils, lymphocytes, and plasma cells. The airway lumen may be occluded by mucus containing hyphal elements and inflammatory cells, especially eosinophils. Squamous metaplasia of the bronchial mucosa commonly develops, and granulomas may form. Rarely, bronchiolitis obliterans or bronchocentric granulomatosis develops.

\section{Immunopathogenesis of ABPA}

As seen in Figure 1, the pathogenesis of ABPA in susceptible persons begins with the inhalation of $A$. fumigatus spores that germinate into hyphae deep within the bronchi. Fragments of hyphae have also been found within the lung parenchyma, potentially resulting in high concentrations of Aspergillus allergens exposed to the respiratory epithelium and immune system [7, 27-29]. These allergens are processed by HLADR2 or HLA-DR5 bearing antigen presenting cells (APC) and presented to $\mathrm{T}$ cells within bronchoalveolar lymphoid tissue (BALT). The resulting $\mathrm{CD}^{+} \mathrm{T}$ cell responses to Aspergillus are skewed toward Th2 response with the production of IL-4, IL-5, and IL-13 cytokines.

6.1. Effect of Aspergillus on Bronchial Epithelium. A. fumigatus spores 3 to $5 \mu \mathrm{m}$ in size are inhaled and germinate deep within the bronchi into hyphae [27]. In addition, fragments of the hyphae can be identified within the interstitial of the pulmonary parenchyma. The implication of this is that there is the potential for high concentrations of A. fumigatus allergens exposed to the respiratory epithelium and immune system. A. fumigatus releases a variety of proteins, including superoxide dismutases, catalases, proteases, ribotoxin, phospholipases, hemolysin, gliotoxin, phthioic acid, and other toxins. The first line of defense against Aspergillus colonization in the lungs is macrophage and neutrophil killing of the conidia and the hyphae. In the development of ABPA, Kauffman's group proposed that Aspergillus proteins have a direct effect on the pulmonary epithelia and macrophage inflammation [30, 31]. They demonstrated that Aspergillus proteases induce epithelial cell detachment. In addition, 


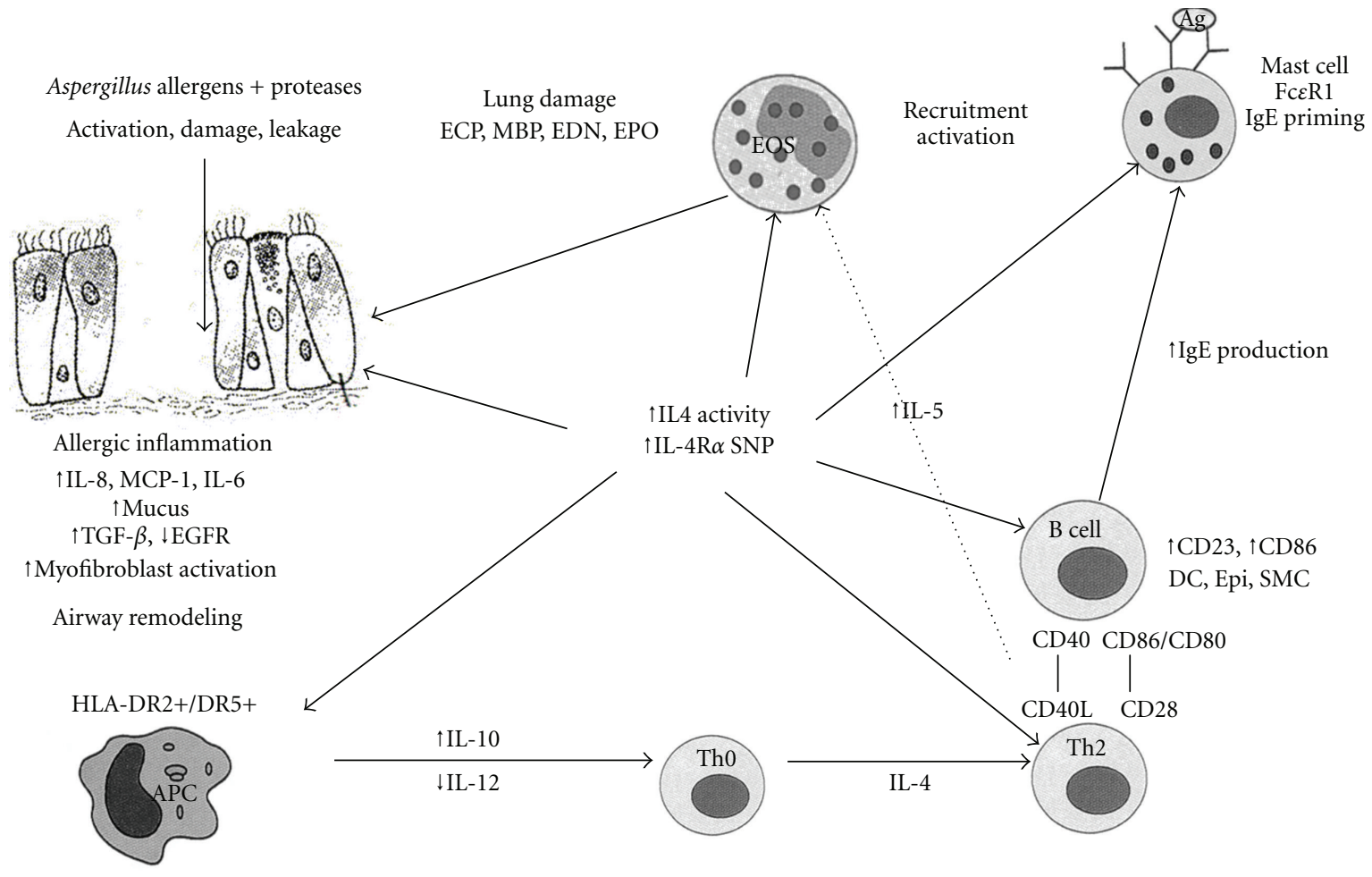

FIGURE 1: Proposed immunopathogenesis of ABPA. In the pathogenesis of ABPA, A. fumigatus proteases have a direct effect on bronchial epithelia causing epithelial cell damage with subsequent stimulation of cytokines and chemokines. Aspergillus proteins are processed via HLA-DR2/DR5 bearing dendritic cells that skew the Th0 response to a Th2 response. Th2 cytokines stimulate IgE synthesis and eosinophil activation. This leads to an eosinophilic inflammatory in the bronchial airways. Abbreviations: Af: Aspergillus fumigates, Asp fx: Aspergillus fumigatus proteins, APC: antigen presenting cell, MBP: major basic protein, ECP: eosinophil cationic protein, EDN: eosinophil derived neurotoxin, VLA: very late activation antigen, VCAM: vascular cell adhesion molecule, CxCR and CCR: chemokines receptors, MCO: monocyte chemotactic protein, sCD23: soluble CD23, cyst-LT: cysteinyl leukotriene.

protease-containing culture filtrates of Aspergillus induce human bronchial cell lines to produce proinflammatory chemokines and cytokines, such as IL-8, IL-6, and MCP-1. Thus, various Aspergillus proteins have significant biologic activity that disrupts the epithelial integrity and induces a monokine inflammatory response. This protease activity allows for enhanced allergen exposure to the bronchoalveolar lymphoid tissue immune system. This is evident by the bronchoalveolar lymphoid tissue synthesis of Aspergillusspecific IgE and IgA antibodies.

An important pathogenic feature of Aspergillus and other microbes is their ability to interact with epithelial cells on the mucosal surface. Macrophage and neutrophil killing of the conidia and hyphae is the first line of defense against colonization in the lungs [32-35]. This is evidenced by an increased susceptibility to invasive pulmonary aspergillosis in patients with chronic granulomatous disease, a disorder of phagocyte killing. A. fumigatus has several virulence factors, including proteolytic enzymes that can interfere with humoral and cellular defense in the airways $[36,37]$. Proteases from Aspergillus and other fungi, including Alternaria and Cladosporium, have been shown to cause epithelial cell detachment, though Aspergillus proteases demonstrated more activity at lower concentrations [36-39].
In addition to damaging the integrity of the epithelial cell layer, Kauffman's group demonstrated that protease containing culture infiltrates of A. fumigatus induced human bronchial cell lines to produce proinflammatory chemokines and cytokines, such as monocyte chemoattractant protein (MCP)-1, IL-8, and IL-6 [30]. MCP-1 has been implicated in directly stimulating the development of Th2 cells [40]. The cytokine-release activity could be ascribed to the proteolytic activities of these extracts [30, 38]. These observations suggested that proteolytic enzymes released by Aspergillus, growing on and between epithelial cells, were responsible for the induction of chemoattractive cytokines by epithelial cells and the corresponding inflammation. It was proposed that induction of the severe inflammatory responses by the direct activation of epithelial cells may cause additional harm to the epithelial cell layer [36]. Destruction of the epithelial cell barrier either by fungal proteases or eosinophilic and neutrophilic inflammation was followed by repair mechanisms, resulting in the influx of serum proteins and extracellular matrix proteins to the luminal side of the epithelium [41]. Because spores and mycelium of $A$. fumigatus have surface structures that are able to interact with extracellular matrix molecules, damage and repair mechanisms of the airway mucosa may facilitate the binding 
of Aspergillus to the damaged sites of the airways. The enhanced release of proteolytic enzymes and allergens on the epithelial surface would induce a continuous inflammatory response and mast cell degranulation, resulting in severe and long-lasting periods of exacerbations of ABPA.

6.2. Aspergillus-Specific Th2 Cells. The immune response to Aspergillus antigens in ABPA patients, as well as allergic asthmatic and CF patients, is characterized by a Th2 $\mathrm{CD}^{+}$ $\mathrm{T}$ lymphocyte response [27, 42-46]. Skin test reactivity to Aspergillus is found in $20 \%-25 \%$ of asthmatic patients [5, $47,48]$ and $31 \%-59 \%$ of CF patients [24, 49]. Although sensitization is common in these populations, only a small percentage of patients develop ABPA.

Several groups have observed T cell lymphoproliferative responses to crude Aspergillus extracts [42, 50-52]. Subsequently, Aspergillus-specific T cell responses were examined and shown to enhance B cell IgE synthesis [52]. In addition, Asp f1 $\mathrm{T}$ cell lines were generated, and the phenotypes were found to be $\mathrm{CD} 4^{+} \mathrm{CD} 25^{+} \mathrm{T}$ cells with the cytokine profile IL $-4^{+}$and IFN $\gamma^{-}$, indicating Th2 $\mathrm{CD}^{+}{ }^{+} \mathrm{T}$ cells [4]. Chauhan et al. [53] subsequently developed $\mathrm{T}$ cell clones from asthmatic ABPA patients and demonstrated either Th2 $\left(\mathrm{IL}-4^{+}, \mathrm{IFN}-\gamma^{-}\right)$or Th0 $\left(\mathrm{IL}-4^{+}, \mathrm{IFN}-\gamma^{+}\right)$patterns. We demonstrated that ABPA subjects have increased frequency of IL $-4^{+} \mathrm{CD}^{+} \mathrm{T}$ cells from Asp f2/f3/f4 stimulated peripheral blood lymphocytes compared to Aspergillus sensitive nonABPA subjects [4]. IL-4 produced by T lymphocytes binds to the IL-4 receptor (IL-4R) on B cells, and in association with the CD40L/CD40 signals, results in IgE isotype switching and B cell proliferation [54]. IL-4 also increases the expression of CD86, which has been linked to eosinophilic airway inflammation and airway hyperresponsiveness after allergen challenge. A central question then is how ABPA patients differ from Aspergillus-sensitive atopic asthmatic and CF patients. We hypothesize that ABPA develops in genetically susceptible individuals with asthma and CF because of increased frequency and/or activity of $A$. fumigatus-specific $\mathrm{Th} 2 \mathrm{CD}^{+}$cells. We further propose that polymorphisms of the interleukin-4 receptor alpha chain (IL-4RA) subunit and HLA-DR2/DR5 are the genetic susceptibility risk factors responsible for the development of ABPA.

6.3. HLA-DR and HLA-DQ. HLA-DR restriction has been shown to be a risk factor for the development of ABPA (Table 4). Chauhan et al. $[53,55,56]$ observed that asthmatic and CF patients who expressed HLA-DR2 and/or DR5 but lacked HLA-DQ2 were at increased risk for ABPA after exposure to A. fumigatus. Within HLA-DR2 and HLA-DR5, there are restricted genotypes. In particular, HLA-DR2 HLA$\mathrm{DRB}^{*} 1501$ and HLA-DRB1*1503 genotypes were reported to provide high relative risk. On the other hand, $40 \%$ to $44 \%$ of non-ABPA atopic Aspergillus-sensitive individuals have the HLA-DR2 and/or DR5 type. Further studies indicated that the presence of HLA-DQ2, especially DQB1*0201, provided protection from the development of ABPA. Furthermore, Chauhan et al. [53] demonstrated that Asp fl allergen has a low-affinity of binding to HLA-DR. This is consistent with
TABLE 4: Genetic risk factors in the development of allergic bronchopulmonary aspergillosis.

(i) HLA-DR restriction and HLA-DQ protection

(1) HLA-DR2

(a) HLA-DRB1*1501 and *HLA-DRB1*1503

(2) HLA-DR5

(3) HLA-DQ2 protective, decreased in ABPA

(a) $\mathrm{DQB}^{*} 0201$

(ii) $I L-4 R A$ polymorphisms

(1) $I L-4 R A$ ile75val

(iii) IL-10 polymorphisms

(1) Promoter-1082 GG genotype

(iv) Surfactant protein A2 ( $S P$-A2) polymorphisms

(1) SP-A2 ala91pro

(v) Cystic fibrosis transmembrane conductance regulator (CFTR) mutations

(1) Heterozygous CFTR mutations in asthmatic patients with ABPA

(vi) Toll-like receptor (TLR) polymorphisms

(1) TLR9 T-1237C polymorphism

Th2 $\mathrm{T}$ cell response previously reported by others in that strong antigen HLA-DR-Ag-TCR affinity binding favored a Th1 cellular response whereas low-affinity binding favored a Th2 humoral response [57-61]. Four major $\mathrm{V} \beta$ chains, $\mathrm{V} \beta$ $3,6,13$, and 14 , reacted to Asp f1.

6.4. IL-4 Responses in ABPA. Human studies and murine models have shown that $\mathrm{CD} 4{ }^{+} \mathrm{Th} 2$ cells and their cytokines are central to the development of ABPA [4, 43-46, 50, 62]. In particular, IL- 4 has a key role in the allergic inflammatory response with effects on various cell populations. Its functions include increasing VCAM-1 expression on endothelial cells, which enhances the recruitment of other immune cells, particularly eosinophils, stimulating proliferation of fibroblasts, important in airway remodeling, and increasing Th2 differentiation while decreasing Th1 differentiation and the production of IFN- $\gamma[63,64]$. IL-4 also has a myriad of effects on B lymphocytes including the stimulation of growth and activation, increasing HLA-DR class II expression important for antigen presentation, and inducing cell surface expression of CD23 and soluble CD23. This cell surface molecule is the low-affinity IgE receptor (FceRII) and an activation marker present on a number of cells including B cells, activated T cells, monocytes, and eosinophils. CD23 plays a role in augmenting B cell IgE synthesis through its interactions with CD21 [65, 66]. Recently, anti-CD23 monoclonal antibody was administered to atopic asthmatic subjects and resulted in decreased serum IgE levels [67]. In addition, IL-4 has a more direct role in IgE isotype switching by B-cells. It should be noted that IL-13 may also stimulate the synthesis of $\operatorname{IgE}$ and is the only other cytokine that has this capability [68-70]. Recently, increased sensitivity to in vitro IL-4 stimulation as measured by enhanced expression of 
the low-affinity IgE receptor (CD23) on B cells was observed in ABPA patients $[43,44]$. This was associated with singlenucleotide polymorphisms of the IL-4 receptor alpha chain (IL-4RA) in $92 \%$ of ABPA subjects, principally the IL-4binding single-nucleotide polymorphism ile75val [29, 45, 46]. This increased sensitivity to IL- 4 is demonstrated by increased expression of CD23 and CD86 on B cells of ABPA subjects and increased CD23 expression during flares of ABPA [29]. CD23 is expressed on a variety of cells, including $\mathrm{B}$ cells, natural killer cells, subpopulations of $\mathrm{T}$ cells, and a subpopulation of dendritic cells. T-cell CD23 and B-cell CD21 form a costimulatory pathway. T-cell CD28 and Bcells CD80 and CD86 costimulatory pathways activate both $\mathrm{T}$ and $\mathrm{B}$ cells, and CD28: CD86 is important in IgE synthesis. CD86 is also found on dendritic cells that have the histamine receptor 2, which skews antigen-specific $\mathrm{T}$ cells to a Th2 response. We have also observed increased CD86 expression on monocyte-derived dendritic cells of ABPA subjects. Thus, antigen-presenting cells such as monocytes and dendritic cells bearing HLA-DR2 and/or HLA-DR5 and increased sensitivity to IL-4 stimulation probably play a critical role in skewing A. fumigatus-specific Th2 responses in ABPA.

6.5. IL-4 Alpha Chain Receptor (IL-4RA) Polymorphisms. The IL-4 receptor is a type I cytokine receptor and exists as a heterodimer that shares a subunit, IL-4 receptor alpha chain (IL-4RA), with the IL-13 receptor alpha (IL-13RA) [71]. There are two types of IL-4 receptors. Type I receptors, found on all lymphohematopoietic cells, are composed of the $I L-4 R A$ and the common gamma chain $(\gamma \mathrm{C})$, which is also a component of IL-2, IL-7, IL-9, IL-15, and IL-21 cytokine receptors [72]. IL-4 receptor type II, also known as the IL13 receptor, is formed by the association of $I L-4 R A$ with the IL-13RA subunits and is located on immune cells, bronchial epithelium, and vascular endothelium. IL-4 stimulates both type I and type II receptors while IL-13 signals through type II receptors.

A potential gain-of-function in the $I L-4 R A$ subunit may be responsible for $\mathrm{B}$ cell hyper-reactivity in ABPA. As a consequence of increased IL-4R activity, proinflammatory cytokines skew $\mathrm{T}$ cell responses to a dominant $\mathrm{Th} 2$ pattern which ultimately contributes to the pathophysiology and progression of ABPA. There are eight naturally occurring single nucleotide polymorphisms (SNPs) of the IL4RA gene: ile75val, glu400ala, cys431arg, ser436leu, ser503pro, gln576arg, ser752ala, and ser786pro reported thus far [7383]. Chromosome 16, which has been associated with asthma, contains the $I L-4 R A$ gene [78]. Studies have identified a number of these SNPs to be associated with atopy prevalence and asthma severity. In 1997 Khurana Hershey et al. [74] initially reported on a high prevalence of atopy and a gain-of-function in the $I L-4 R A$ as measured by increased CD23 expression in patients with gln576arg and a later study found that this allele correlated with asthma severity [80]. Hershey's group found that the presence of two variants, val75 and arg576 together, resulted in elevated IL-4 dependent CD23 expression which was not observed when these SNPs were present alone [83]. In our studies, the presence of the val75 allele, located within the IL4 binding region, was found in $87.5 \%$ of ABPA subjects examined, while the cytoplasmic SNPs were present much less frequently at $27.3 \%$ for ala $400,27.3 \%$ pro503, and $27.3 \%$ $\arg 576$, and $9.1 \%$ arg 431 . Although these alleles, particularly val75, appear to be common in the general population, their high prevalence in ABPA suggests that they may be a risk factor in the development of the disease (Table 4).

6.6. IL-10 Polymorphisms. Brouard and coworkers [84] recently reported another genetic risk, the association of the -1082GG genotype of the IL-10 promoter with colonization with $A$. fumigatus and the development of ABPA in CF (Table 4). The $-1082 G G$ polymorphism has been associated with increased IL-10 synthesis; whereas the $-1082 \mathrm{~A}$ allele has lower IL-10 synthesis. Thus, dendritic cells expressing HLADR2/DR5, increased IL-10 synthesis, and increased sensitivity to IL-4 stimulation due to $I L-4 R A$ polymorphisms, may be responsible for skewing Aspergillus-specific Th2 responses in ABPA.

6.7. Surfactant Protein A2 (SP-A2) Polymorphisms. Recently, Saxena et al. [85] reported that ABPA patients with polymorphisms (ala91pro, arg94arg) in the collagen region of pulmonary surfactant protein A2 ( $S P-A 2)$ had more elevated total IgE levels and higher percentages of eosinophilia than observed in those patients who lacked the SNPs (Table 4). They also found that $80 \%$ of patients carrying both alleles had ABPA $(P=.0079$, OR $=10.4)$, while only $50 \%$ and $60 \%$ of patients carrying each allele, individually, were ABPA subjects, suggesting an additive effect. How these SNPs affect SP-A has not yet been elucidated, but the collagen region spanning both $\mathrm{SNPs}$ has been shown to associate with receptors of alveolar macrophages [86], which are important in protecting against Aspergillus colonization [32]. It is theorized that changes in conformation or affinity of SP-A2 may decrease these interactions and compromise host defense.

6.8. Cystic Fibrosis Transmembrane Conductance Regulator (CFTR) Gene Mutations. Because ABPA is found in highest incidence among atopic patients with CF, Miller et al. [87] examined mutations in the cystic fibrosis transmembrane conductance regulator gene (CFTR) in subjects without CF (Table 4). Their group reported that mutations were present at a higher frequency in asthmatic patients who developed ABPA, 6 of 21 (28.5\%), versus control asthmatics, 2 of $43(4.6 \%)$. These ABPA patients were heterozygous for the mutations ( 1 patient was compound heterozygote and reclassified as atypical (CF), did not have a clinical diagnosis of CF, and had sweat chlorides $<60 \mathrm{mEq} / \mathrm{L}$. Although the abnormal airway mucus in CF is thought to be a susceptibility factor for ABPA due to enhanced trapping of Aspergillus spores, it is unclear what effect heterozygous CFTR mutations may have on mucus quality in asthmatic airways.

6.9. Toll-Like Receptor (TLR) Polymorphisms. Wang et al. [88] examined Toll-like receptor (TLR) polymorphisms of 
TLR2, TLR4, and TLR9 in cavitary pulmonary aspergillosis (CCPA), and severe asthma associated with fungal sensitization (SAFS). TLR-4 is among the major receptors for Aspergillus hyphae and plays an important part in innate host defense as TLR-4 deficient mice have increased susceptibility to invasive aspergillosis [88]. In CCPA patients, there was significantly increased frequency of the G allele of TLR4 on asp299gly. ABPA patients had increased frequency of allele C for the TLR9 T-1237C polymorphism compared to control patients. However, in SAFS patients who are predominantly Aspergillus sensitive, there was no association of polymorphisms of TLR2, TLR4, or TLR9. TLR-9 is a receptor that recognizes CPG motifs prevalent in bacterial and viral DNA. Aspergillus hyphae and conidia do signal through TLR-9 on murine neutrophils [89]. TLR-9 deficient mice demonstrate greater conidial and hyphal damage. In addition, Lazarus et al. [90] reported that TLR9 polymorphisms have been associated with increased risk of asthma. Novak et al. [91] reported that the TLR9 C allele of T-1237C decreases expression. Thus, decreased TLR-9 protective function may be an underlying susceptibility in the development of ABPA.

There are additional genetic risk factors in the development of allergy to fungi that include integrin $\beta 3$ (ITGB3) polymorphisms and chitinase polymorphisms. However, they have not been examined in ABPA.

6.10. Integrin $\beta 3$ (ITGB3). ITGB3 encodes a $\beta$-integrin that comprises part of the platelet and monocyte specific heterodimeric receptor for fibrinogen and the receptor for vitronectin. Gerold et al. [92] reported that vitronectin specifically bound triacylated lipopeptides. Vitronectin facilitates the delivery of lipopeptides to the vitronectin receptor which is part of the TLR-2 activation complex. Vitronectin binds to 6 different integrin receptors by an arg-gly-asp (RGD) motif; the main receptor, though, is integrin $\alpha \mathrm{v} \beta 3$ (integrin $\beta 3$ ). Recently, Weiss et al. [93] reported single nucleotide polymorphisms (SNP) of ITGB3 associated with asthma and sensitization to mold allergens. Bromley and Donaldson [94] demonstrated that the RGD peptide sequence is the ligand for integrin $\beta 3$. Whether this polymorphism is a risk factor in the development of ABPA needs to be examined.

6.11. Chitinases. Chitin is a major structural component of the outer coatings of many organisms such as fungi, parasitic nematodes, and arthropods [95, 96]. Chitin has been shown to skew the immune system towards Th1 response by suppressing Th2-mediated IgE production and lung eosinophilia in allergic mice. In humans, acidic mammalian chitinase degrade these chitins, thereby shifting the response toward a Th2 inflammatory response. Elevated chitinase has been associated with asthma and elevated $\mathrm{IgE}$ levels perhaps through an IL-13 pathway [97, 98]. Furthermore, polymorphisms in the promoter of acidic mammalian chitinase have been associated with atopic asthma and elevated IgE levels. Their role in ABPA is yet to be determined.

6.12. Adhesion Molecules. Mutation of a number of adhesion molecules has been associated with asthma and decline of pulmonary function. However, they have not been studied for association with sensitivity to A. fumigatus, colonization with A. fumigatus, or development of ABPA. These include A disintegrin and metalloprotease 33 gene (ADAM33), filaggrin $(F L G)$, protocadherin $1(P C D H 1)$, plasma urokinase plasminogen activator (PLAUR), and E-cadherin genes. These molecules play an important role in maintaining the integrity of the airway epithelium. Kauffman's group reported that $A$. fumigatus and other fungal proteases disrupt bronchial epithelial integrity $[30,31]$. Furthermore, Fairs et al. [17] identified that IgE sensitization to A. fumigatus and colonization with A. fumigatus in asthmatics was associated with a more rapid decline of pulmonary function. Further studies are needed to examine whether A. fumigatus proteases are more damaging to bronchial epithelial integrity when mutations of these adhesions molecules are present.

6.13. A Disintegrin and Metalloprotease 33 Gene (ADAM33). ADAM33 is a member of the ADAM family, which is involved in cell adhesion, cell fusion, cell signaling, and proteolysis. ADAM33 is expressed on airway smooth muscle cells and fibroblasts $[99,100]$. It has been proposed to contribute to airway remodeling in asthma. SNPs of ADAM33 have been associated with reduced lung function and rapid decline of FEV-1 in asthma.

6.14. Filaggrin (FLG). Filaggrin contributes to the skin barrier and mutations of FLG have been associated with eczema. In addition, FLG SNPs have been associated with the development of asthma [101].

6.15. Protocadherin 1 (PCDH1). Protocadherins play an important role in cell adhesion and organ development. Protocadherins 1 is expressed in the apical adhesion complex of airway epithelia cells. It is postulated that PCDH1 may be important in epithelial integrity of the airways. Koppelman et al. [102] reported that polymorphisms of $P C D H 1$ play a role in the development of bronchial hyperresponsiveness in asthma.

6.16. Plasma Urokinase Plasminogen Activator (PLAUR). PLAUR may play a role in the pathogenesis of airway remodeling in asthma. Barton et al. [103] reported that SNPs of PLAUR are associated with development of asthma and lung function decline in asthma.

6.17. E-Cadherin. E-cadherin forms cell-cell contacts promoting integrity of the airway epithelium [104]. Reduction of E-cadherin is observed during airway responses and results in increased epithelial permeability and increased airway hyperresponsiveness.

\section{Treatment}

Treatment is designed first to control the acute episodes and then to limit the development of chronic lung disease [19-23]. Most cases of ABPA require treatment with systemic 
corticosteroids, and the treatment of choice is prednisone. Steroid therapy rapidly clears the eosinophilic infiltrates and the associated symptoms, although it is less effective at treating mucus impaction. In asthmatic ABPA patients, the usual starting dose is $0.5 \mathrm{mg} / \mathrm{kg} / \mathrm{day}$, taken each morning, and this dose is maintained for 2 to 4 weeks while following the patient clinically and checking the chest radiograph for resolution of the acute process. After this induction treatment, the dose of prednisone should be reduced to $0.5 \mathrm{mg} / \mathrm{kg}$ given on alternate days. If mucus impaction persists and is associated with atelectasis, bronchoscopy should be performed to confirm the diagnosis and to attempt to remove the mucus plugs. Following resolution of the acute process, the dose of prednisone should be reduced over 1 to 3 months. Chronic treatment with corticosteroids is controversial, especially in adults, because only minorities of patients with ABPA are at risk of chronic lung disease. The relationship between acute episodes and lung damage is unclear, and the precise dose of prednisone is not certain, since acute exacerbations may continue while the patients are on low doses of steroids.

Children with ABPA usually have CF and may need treatment with higher corticosteroid dosing and long-term corticosteroids to prevent progressive lung damage. Stevens et al. [23] in the Cystic Fibrosis Foundation Consensus Conference report recommended in ABPA CF patients an initial dose of $2 \mathrm{mg} / \mathrm{kg} /$ day of prednisone for 1 week. This is then reduced to $1 \mathrm{mg} / \mathrm{kg} /$ day for 1 week that was followed by reducing to alternate day dosing. This prednisone dose is then gradual tapered typically. We usually maintain therapy with a dose of $0.5 \mathrm{mg} / \mathrm{kg}$ on alternate days for 3 months and then, after 3 months, the dose of prednisone is tapered over a further 3 months while checking the chest radiograph and the serum IgE level for evidence of relapse. Initially, the serum IgE level should be checked at every visit and, if the level increases by twofold or more, the steroid dose should be increased. We recommend that patients are followed with serum IgE levels and chest radiographs every 6 months for the first 1 to 2 years, and then, if the child remains in remission, it should be possible to reduce the frequency of these studies. Unfortunately, this high and prolonged corticosteroid treatment may induce diabetes in these CF patients. Treatment with itraconazole and omalizumab should be considered as adjunctive treatment of ABPA (see below). Furthermore, their use may be helpful in preventing exacerbation of ABPA in CF patients. Monitoring of ABPA in CF patients is done at multiple levels. These include clinical symptoms of dyspnea, cough and wheezing, pulmonary function studies, serum IgE levels, IgE and IgG specific anti-A. fumigatus antibodies, blood eosinophilia, and blood glucose.

The antifungal agent itraconazole has been used to reduce the doses of steroids that are required $[105,106]$. Initially, there were only open nonrandomized studies that indicated that itraconazole is a useful adjunct to systemic corticosteroid therapy. Two recent randomized controlled trials have also favored intraconazole use. A double-blind, randomized, placebo-controlled trial of itraconazole $200 \mathrm{mg}$ twice daily dose resulted in decreased IgE levels and an increase in pulmonary function and exercise tolerance. Another randomized, controlled trial showed that treatment of stable ABPA in adults with $400 \mathrm{mg} /$ day itraconazole resulted in a significant reduction in sputum eosinophil count, sputum eosinophilic cationic protein levels, serum IgE concentrations, and Aspergillus-specific IgG. There was also a reduction in episodes of exacerbation requiring treatment with systemic steroids. In the treatment of children with ABPA, we have used a dose of $10 \mathrm{mg} / \mathrm{kg} /$ day of itraconazole. Omalizumab, anti-IgE monoclonal antibody, has been used in uncontrolled reports. Anecdotally, it has been effective, but a randomized controlled trial is necessary.

There is no place for immunotherapy in children with ABPA, since it is ineffective and potentially dangerous. Inhaled anti-inflammatory agents, such as cromoglycate and corticosteroids are not generally thought to be effective. The role of inhaled spores in the pathogenesis of ABPA is unclear, but there is a seasonal incidence of ABPA that is probably related to seasonal changes in mold spore counts. Therefore, it is reasonable to advise patients with ABPA to avoid exposure to places with high spore counts, such as damp basements, barns, and compost heaps.

\section{Prognosis}

The prognosis of ABPA is good if the disease is detected early and treatment started promptly. It is important that the diagnosis is made and treatment commenced before there is permanent lung damage from bronchiectasis. In such patients, there should be no progression of the disease, although relapses can occur many years later, and longterm followup is recommended. In children with CF, the relapses seem to be more frequent than they are in patients with asthma, and careful surveillance is necessary to ensure resolution of the disease process. In some CF patients, it is difficult to wean the steroids without an increase in symptoms, such as dyspnea and wheezing; whether this is due to the underlying CF lung disease or due to patients going from stage II to stage III ABPA on withdrawal of steroids is unclear. Symptoms are not a reliable guide to therapy; therefore, it is important to reevaluate the chest radiograph and the serum IgE at regular intervals until a long-term remission is established.

\section{Conclusions}

ABPA occurs with a world-wide distribution in a significant number of patients with $\mathrm{CF}$ and less frequently in those with asthma. Early diagnosis and treatment are essential in preventing end-stage progression. The development of ABPA is probably the combination of many genetic susceptibility factors, gene-gene interactions, and environmental exposure which work together. Understanding of the genetic risks and immunopathogenesis of ABPA hopefully will lead to improved early diagnosis and improved treatment of ABPA. 


\section{Abbreviations}

ABPA: Allergic bronchopulmonary aspergillosis

Af: $\quad$ Aspergillus fumigatus

CFTR: Cystic fibrosis transmembrane conductance regulator

IL-4RA: IL-4 receptor alpha chain

TARC: Thymus and activation-regulated chemokine

SP-A2: Surfactant protein A2 polymorphisms.

\section{References}

[1] K. Hinson, A. Moon, and N. Plummer, "Broncho-pulmonary aspergillosis," Thorax, vol. 7, pp. 317-333, 1952.

[2] R. Patterson and T. M. Golbert, "Hypersensitivity disease of the lung," University of Michigan Medical Center journal, vol. 34, no. 1, pp. 8-11, 1968.

[3] R. G. Slavin, D. J. Stanczyk, A. J. Lonigro, and G. O. Broun, "Allergic bronchopulmonary aspergillosis-A north American rarity. Clinical and immunologic characteristics," The American Journal of Medicine, vol. 47, no. 2, pp. 306-313, 1969.

[4] A. P. Knutsen, K. R. Mueller, A. D. Levine, B. Chouhan, P. S. Hutcheson, and R. G. Slavin, "Asp f I CD4+ T(H2)-like T-cell lines in allergic bronchopulmonary aspergillosis," Journal of Allergy and Clinical Immunology, vol. 94, no. 2, pp. 215-221, 1994.

[5] P. A. Greenberger and R. Patterson, "Allergic bronchopulmonary aspergillosis and the evaluation of the patient with asthma," Journal of Allergy and Clinical Immunology, vol. 81, no. 4, pp. 646-650, 1988.

[6] P. Laufer, J. N. Fink, W. T. Burns et al., "Allergic bronchopulmonary aspergillosis in cystic fibrosis," Journal of Allergy and Clinical Immunology, vol. 73, pp. 44-48, 1984.

[7] R. G. Slavin, C. W. Bedrossian, P. S. Hutcheson et al., "A pathologic study of allergic bronchopulmonary aspergillosis," Journal of Allergy and Clinical Immunology, vol. 81, no. 4, pp. 718-725, 1988.

[8] S. Paris, E. Boisvieux-Ulrich, B. Crestani et al., "Internalization of Aspergillus fumigatus conidia by epithelial and endothelial cells," Infection and Immunity, vol. 65, no. 4, pp. 1510-1514, 1997.

[9] H. S. Nelson, S. J. Szefler, J. Jacobs, K. Huss, G. Shapiro, and A. L. Sternberg, "The relationships among environmental allergen sensitization, allergen exposure, pulmonary function, and bronchial hyperresponsiveness in the childhood asthma management program," Journal of Allergy and Clinical Immunology, vol. 104, no. 4 I, pp. 775-785, 1999.

[10] M. Zureik, C. Neukirch, B. Leynaert, R. Liard, J. Bousquet, and F. Neukirch, "Sensitisation to airborne moulds and severity of asthma: cross sectional study from European Community respiratory health survey," British Medical Journal, vol. 325, no. 7361, pp. 411-414, 2002.

[11] B. R. O’Driscoll, L. C. Hopkinson, and D. W. Denning, "Mold sensitization is common amongst patients with severe asthma requiring multiple hospital admissions," $B M C$ Pulmonary Medicine, vol. 5, article 4, 2005.

[12] J. K. Peat, E. Tovey, C. M. Mellis, S. R. Leeder, and A. J. Woolcock, "Importance of house dust mite and Alternaria allergens in childhood asthma: an epidemiological study in two climatic regions of Australia," Clinical and Experimental Allergy, vol. 23, no. 10, pp. 812-820, 1993.

[13] F. D. Martinez, . Buist, . Warner et al., "Progression of asthma from childhood to adolescence," European Respiratory Review, vol. 40, pp. 8-10, 1997.

[14] P. C. Stark, H. A. Burge, L. M. Ryan, D. K. Milton, and D. R. Gold, "Fungal levels in the home and lower respiratory tract illnesses in the first year of life," American Journal of Respiratory and Critical Care Medicine, vol. 168, no. 2, pp. 232-237, 2003.

[15] R. J. Delfino, R. S. Zeiger, J. M. Seltzer et al., "The effect of outdoor fungal spore concentrations on daily asthma severity," Environmental Health Perspectives, vol. 105, no. 6, pp. 622-635, 1997.

[16] D. W. Denning, B. R. O’Driscoll, C. M. Hogaboam, P. Bowyer, and R. M. Niven, "The link between fungi and severe asthma: a summary of the evidence," European Respiratory Journal, vol. 27, no. 3, pp. 615-626, 2006.

[17] A. Fairs, J. Agbetile, B. Hargadon et al., "IgE sensitisation to Aspergillus fumigatus is associated with reduced lung function in asthma," American Journal of Respiratory and Critical Care Medicine, vol. 182, no. 11, pp. 1362-1368, 2010.

[18] R. Crameri, "Molecular cloning of Aspergillus fumigatus allergens and their role in allergic bronchopulmonary aspergillosis," in Fungal Allergy and Pathogenicity. Chemical Immunology, M. Breitenbach, R. Crameri, and S. B. Lehrer, Eds., vol. 81, pp. 73-93, Karger, Basel, Switzerland, 2002.

[19] P. A. Greenberger, "Allergic bronchopulmonary aspergillosis," Journal of Allergy and Clinical Immunology, vol. 110, no. 5, pp. 685-692, 2002.

[20] P. A. Greenberger, T. P. Miller, M. Roberts, and L. L. Smith, "Allergic bronchopulmonary aspergillosis in patients with and without evidence of bronchiectasis," Annals of Allergy, vol. 70, no. 4, pp. 333-338, 1993.

[21] P. A. Greenberger, "Allergic bronchopulmonary aspergillosis," in Allergy: Principles and Practice, N. F. Adkinson Jr., J. W. Yunginger, W. W. Busse, B. S. Bochner, S. T. Holgate, and F. E. R. Simons, Eds., pp. 1353-1371, Mosby, St. Louis, Mo, USA, 2003.

[22] R. Patterson, P. A. Greenberger, R. C. Radin, and M. Roberts, "Allergic bronchopulmonary aspergillosis: staging as an aid to management," Annals of Internal Medicine, vol. 96, no. 3, pp. 286-291, 1982.

[23] D. A. Stevens, R. B. Moss, V. P. Kurup et al., “ Allergic bronchopulmonary aspergillosis in cystic fibrosis-state of the art: cystic fibrosis foundation consensus conference," Clinical Infectious Diseases, vol. 37, no. 3, pp. S225-S264, 2003.

[24] S. Hemmann, W. H. Nikolaizik, M. H. Schöni, K. Blaser, and R. Crameri, "Differential IgE recognition of recombinant Aspergillus fumigatus allergens by cystic fibrosis patients with allergic bronchopulmonary aspergillosis or Aspergillus allergy," European Journal of Immunology, vol. 28, no. 4, pp. 1155-1160, 1998.

[25] P. Latzin, D. Hartl, N. Regamey, U. Frey, M. H. Schoeni, and C. Casaulta, "Comparison of serum markers for allergic bronchopulmonary aspergillosis in cystic fibrosis," European Respiratory Journal, vol. 31, no. 1, pp. 36-42, 2008.

[26] D. Hartl, P. Latzin, G. Zissel, M. Krane, S. Krauss-Etschmann, and M. Griese, "Chemokines indicate allergic bronchopulmonary aspergillosis in patients with cystic fibrosis," American Journal of Respiratory and Critical Care Medicine, vol. 173, no. 12, pp. 1370-1376, 2006. 
[27] A. P. Knutsen, "Immunopathogenesis of allergic bronchopulmonary aspergillosis," Frontiers in Bioscience, vol. 8, pp. 589602, 2003.

[28] A. P. Knutsen, "Genetic risk factors in the development of allergic bronchopulmonary aspergillosis," Current Trends in Immunology, vol. 7, pp. 47-54, 2006.

[29] A. P. Knutsen, B. Kariuki, L. A. Santiago et al., "HLADR, IL-4RA, and IL-10: genetic risk factors in allergic bronchopulmonary aspergillosis," Pediatric Asthma, Allergy and Immunology, vol. 21, no. 4, pp. 185-190, 2008.

[30] H. F. Kauffman, J. F. Christomee, M. A. Van De Riet, A. J. B. Timmerman, and P. Borger, "Protease-dependent activation of epithelial cells by fungal allergens leads to morphologic changes and cytokine production," Journal of Allergy and Clinical Immunology, vol. 105, no. 6, pp. 1185-1193, 2000.

[31] J. F. C. Tomee, H. F. Kauffman, A. H. Klimp, J. G. R. De Monchy, G. H. Koeter, and A. E. J. Dubois, "Immunologic significance of a collagen-derived culture filtrate containing proteolytic activity in Aspergillus-related diseases," Journal of Allergy and Clinical Immunology, vol. 93, no. 4, pp. 768-778, 1994.

[32] A. Schaffner, H. Douglas, and A. Braude, "Selective protection against conidia by mononuclear and against mycelia by polymorphonuclear phagocytes in resistance to aspergillus. Observations on these two lines of defense in vivo and in vitro with human and mouse phagocytes," Journal of Clinical Investigation, vol. 69, no. 3, pp. 617-631, 1982.

[33] E. Roilides, K. Uhlig, D. Venzon, P. A. Pizzo, and T. J. Walsh, "Prevention of corticosteroid-induced suppression of human polymorphonuclear leukocyte-induced damage of Aspergillus fumigatus hyphae by granulocyte colonystimulating factor and gamma interferon," Infection and Immunity, vol. 61, no. 11, pp. 4870-4877, 1993.

[34] E. Brummer, A. Maqbool, and D. A. Stevens, "Protection of bronchoalveolar macrophages by granulocyte-macrophage colony-stimulating factor against dexamethasone suppression of fungicidal activity for aspergillus fumigatus conidia," Medical Mycology, vol. 39, no. 6, pp. 509-515, 2001.

[35] E. Brummer, A. Maqbool, and D. A. Stevens, "In vivo GM-CSF prevents dexamethasone suppression of killing of Aspergillus fumigatus conidia by bronchoalveolar macrophages," Journal of Leukocyte Biology, vol. 70, no. 6, pp. 868-872, 2001.

[36] H. K. Kauffman and J. F. C. Tomee, "Inflammatory cells and airway defense against Aspergillus fumigatus," Immunology and Allergy Clinics of North America, vol. 18, no. 3, pp. 619$640,1998$.

[37] J. F. CH. Tomee and H. F. Kauffman, "Putative virulence factors of Aspergillus fumigatus," Clinical and Experimental Allergy, vol. 30, no. 4, pp. 476-484, 2000.

[38] J. F. C. Tomee, A. T. J. Wierenga, P. S. Hiemstra, and H. F. Kauffman, "Proteases from Aspergillus fumigatus induce release of proinflammatory cytokines and cell detachment in airway epithelial cell lines," Journal of Infectious Diseases, vol. 176, no. 1, pp. 300-303, 1997.

[39] J. F. C. Tomee, T. S. Van der Werf, J. P. Latge, G. H. Koeter, A. E. J. Dubois, and H. F. Kauffman, "Serologic monitoring of disease and treatment in a patient with pulmonary aspergilloma," American Journal of Respiratory and Critical Care Medicine, vol. 151, no. 1, pp. 199-204, 1995.

[40] L. Gu, S. Tseng, R. M. Horner, C. Tam, M. Loda, and B. J. Rollins, "Control of $\mathrm{T}(\mathrm{H}) 2$ polarization by the chemokine monocyte chemoattractant protein-1," Nature, vol. 404, no. 6776 , pp. 407-411, 2000.
[41] C. G. A. Persson, J. S. Erjefält, I. Erjefält, M. C. Kursgren, M. C. Nilsson, and F. Sundler, "Epithelial shedding-restitution as a causative process in airway inflammation," Clinical and Experimental Allergy, vol. 26, no. 7, pp. 746-755, 1996.

[42] A. P. Knutsen, B. Chauhan, and R. G. Slavin, "Cell-mediated immunity in allergic bronchopulmonary aspergillosis," Immunology and Allergy Clinics of North America, vol. 18, no. 3, pp. 575-599, 1998.

[43] S. Khan, J. S. McClellan, and A. P. Knutsen, "Increased sensitivity to IL-4 in patients with allergic bronchopulmonary aspergillosis," International Archives of Allergy and Immunology, vol. 123, no. 4, pp. 319-326, 2000.

[44] A. P. Knutsen, P. S. Hutchinson, G. M. Albers, J. Consolino, J. Smick, and V. P. Kurup, "Increased sensitivity to IL-4 in cystic fibrosis patients with allergic bronchopulmonary aspergillosis," Allergy, vol. 59, no. 1, pp. 81-87, 2004.

[45] A. P. Knutsen, B. Kariuki, J. D. Consolino, and M. R. Warrier, "IL-4 alpha chain receptor (IL-4R $\alpha$ ) polymorphisms in allergic bronchopulmonary sspergillosis," Clinical and Molecular Allergy, vol. 3, pp. 1-6, 2006.

[46] A. P. Knutsen, "Genetic and respiratory tract risk factors for aspergillosis: ABPA and asthma with fungal sensitization," Medical Mycology, vol. 44, no. 1, pp. 61-70, 2006.

[47] R. Crameri, S. Hemmann, C. Ismail, G. Menz, and K. Blaser, "Disease-specific recombinant allergens for the diagnosis of allergic bronchopulmonary aspergillosis," International Immunology, vol. 10, no. 8, pp. 1211-1216, 1998.

[48] H. J. Schwartz, K. M. Citron, and E. H. Chester, "A comparison of the prevalence of sensitization to Aspergillus antigens among asthmatics in Cleveland and London," Journal of Allergy and Clinical Immunology, vol. 62, no. 1, pp. 9-14, 1978.

[49] E. A. Valletta, C. Braggion, and G. Mastella, "Sensitization to Aspergillus and allergic bronchopulmonary Aspergillosis in a cystic fibrosis population," Pediatric Asthma, Allergy and Immunology, vol. 7, no. 1, pp. 43-49, 1993.

[50] A. P. Knutsen and R. G. Slavin, "In vitro T cell responses in patients with cystic fibrosis and allergic bronchopulmonary aspergillosis," Journal of Laboratory and Clinical Medicine, vol. 113, no. 4, pp. 428-435, 1989.

[51] R. G. Slavin, P. S. Hutcheson, and A. P. Knutsen, "Participation of cell-mediated immunity in allergic bronchopulmonary aspergillosis," International Archives of Allergy and Applied Immunology, vol. 83, no. 4, pp. 337-340, 1987.

[52] A. P. Knutsen, K. R. Mueller, P. S. Hutcheson, and R. G. Slavin, "T- and B-cell dysregulation of IgE synthesis in cystic fibrosis patients with allergic bronchopulmonary aspergillosis," Clinical Immunology and Immunopathology, vol. 55, no. 1, pp. 129-138, 1990.

[53] B. Chauhan, A. P. Knutsen, P. S. Hutcheson, R. G. Slavin, and C. J. Bellone, "T cell subsets, epitope mapping, and HLA-restriction in patients with allergic bronchopulmonary aspergillosis," Journal of Clinical Investigation, vol. 97, no. 10, pp. 2324-2331, 1996.

[54] L. B. Bacharier and R. S. Geha, "Molecular mechanisms of IgE regulation," Journal of Allergy and Clinical Immunology, vol. 105, no. 2, pp. S547-S558, 2000.

[55] B. Chauhan, L. Santiago, D. A. Kirschmann et al., "The Association of HLA-DR Alleles and T Cell Activation with Allergic Bronchopulmonary Aspergillosis," Journal of Immunology, vol. 159, no. 8, pp. 4072-4076, 1997.

[56] B. Chauhan, L. Santiago, P. S. Hutcheson et al., "Evidence for the involvement of two different MHC class II regions 
in susceptibility or protection in allergic bronchopulmonary aspergillosis," Journal of Allergy and Clinical Immunology, vol. 106, no. 4, pp. 723-729, 2000.

[57] J. R. Lamb, J. A. Higgins, C. Hetzel, J. D. Hayball, R. A. Lake, and R. E. O'Hehir, "The effects of changes at peptide residues contacting MHC class II T-cell receptor on antigen recognition and human Th0 cell effector function," Immunology, vol. 85, no. 3, pp. 447-454, 1995.

[58] D. C. Tsitoura, A. Verhoef, C. M. Gelder, R. E. O’Hehir, and J. R. Lamb, "Altered T cell ligands derived from a major house dust mite allergen enhance IFN- $\gamma$ but not IL-4 production by human CD4+ T cells," Journal of Immunology, vol. 157, no. 5, pp. 2160-2165, 1996.

[59] C. Pfeiffer, J. Stein, S. Southwood, H. Ketelaar, A. Sette, and K. Bottomly, "Altered peptide ligands can control CD4 T lymphocyte differentiation in vivo," Journal of Experimental Medicine, vol. 181, no. 4, pp. 1569-1574, 1995.

[60] B. D. Evavold, J. Sloan-Lancaster, B. L. Hsu, and P. M. Allen, "Separation of T helper 1 clone cytolysis from proliferation and lymphokine production using analog peptides," Journal of Immunology, vol. 150, no. 8 I, pp. 3131-3140, 1993.

[61] L. Racioppi, F. Ronchese, L. A. Matis, and R. N. Germain, "Peptide-major histocompatibility complex class II complexes with mixed agonist/antagonist properties provide evidence for ligand-related differences in $\mathrm{T}$ cell receptordependent intracellular signaling," Journal of Experimental Medicine, vol. 177, no. 4, pp. 1047-1060, 1993.

[62] V. P. Kurup, B. W. P. Seymour, H. Choi, and R. L. Coffman, "Particulate Aspergillus fumigatus antigens elicit a $\mathrm{T}(\mathrm{H} 2)$ response in BALB/c mice," Journal of Allergy and Clinical Immunology, vol. 93, no. 6, pp. 1013-1020, 1994.

[63] R. P. Schleimer, S. A. Sterbinsky, J. Kaiser et al., "IL-4 induces adherence of human eosinophils and basophils but not neutrophils to endothelium: association with expression of VCAM-1," Journal of Immunology, vol. 148, no. 4, pp. 1086-1092, 1992.

[64] R. Moser, J. Fehr, and P. L. B. Bruijnzeel, "IL-4 controls the selective endothelium-driven transmigration of eosinophils from allergic individuals," Journal of Immunology, vol. 149, no. 4, pp. 1432-1438, 1992.

[65] J. Y. Bonnefoy, J. F. Gauchat, P. Life, P. Graber, J. P. Aubry, and S. Lecoanet-Henchoz, "Regulation of IgE synthesis by CD23/CD21 interaction," International Archives of Allergy and Immunology, vol. 107, no. 1-3, pp. 40-42, 1995.

[66] J.-Y. Bonnefoy, "Pairs of surface molecules involved in human IgE regulation: CD23-CD21 and CD40-CD40L," European Respiratory Journal, Supplement, vol. 9, no. 22, pp. 63s-66s, 1996.

[67] L. J. Rosenwasser, W. W. Busse, R. G. Lizambri, T. A. Olejnik, and M. C. Totoritis, "Allergic asthma and an anti-CD23 mAb (IDEC-152): results of a phase I, single-dose, dose-escalating clinical trial," Journal of Allergy and Clinical Immunology, vol. 112, no. 3, pp. 563-570, 2003.

[68] D. Vercelli, H. H. Jabara, K. I. Arai, and R. S. Geha, "Induction of human IgE synthesis requires interleukin 4 and T/B cell interactions involving the T cell receptor/CD3 complex and MHC class II antigens," Journal of Experimental Medicine, vol. 169, no. 4, pp. 1295-1307, 1989.

[69] J. Punnonen, G. Aversa, B. G. Cocks et al., "Interleukin 13 induces interleukin 4-independent IgG4 and IgE synthesis and CD23 expression by human B cells," Proceedings of the National Academy of Sciences of the United States of America, vol. 90, no. 8, pp. 3730-3734, 1993.
[70] T. Defrance, P. Carayon, G. Billian et al., "Interleukin 13 is a B cell stimulating factor," Journal of Experimental Medicine, vol. 179, no. 1, pp. 135-143, 1994.

[71] K. Nelms, A. D. Keegan, J. Zamorano, J. J. Ryan, and W. E. Paul, "The IL-4 receptor: signaling mechanisms and biologic functions," Annual Review of Immunology, vol. 17, pp. 701738, 1999.

[72] T. Habib, A. Nelson, and K. Kaushansky, "IL-21: a novel IL2-family lymphokine that modulates B, T, and natural killer cell responses," Journal of Allergy and Clinical Immunology, vol. 112, no. 6, pp. 1033-1045, 2003.

[73] G. K. Khurana Hershey, "IL-13 receptors and signaling pathways: an evolving web," Journal of Allergy and Clinical Immunology, vol. 111, no. 4, pp. 677-690, 2003.

[74] G. K. Khurana Hershey, M. F. Friedrich, L. A. Esswein, M. L. Thomas, and T. A. Chatila, "The association of atopy with a gain-of-function mutation in the $\alpha$ subunit of the interleukin-4 receptor," New England Journal of Medicine, vol. 337, no. 24, pp. 1720-1725, 1997.

[75] K. Deichmann, J. Bardutzky, J. Forster, A. Heinzmann, and J. Kuehr, "Common polymorphisms in the coding part of the IL4-Receptor gene," Biochemical and Biophysical Research Communications, vol. 231, no. 3, pp. 696-697, 1997.

[76] S. Kruse, T. Japha, M. Tedner et al., "The polymorphisms S503P and Q576R in the interleukin-4 receptor $\alpha$ gene are associated with atopy and influence the signal transduction," Immunology, vol. 96, no. 3, pp. 365-371, 1999.

[77] C. Ober, S. A. Leavitt, A. Tsalenko et al., "Variation in the interleukin 4-receptor $\alpha$ gene confers susceptibility to asthma and atopy in ethnically diverse populations," American Journal of Human Genetics, vol. 66, no. 2, pp. 517-526, 2000.

[78] K. A. Deichmann, A. Heinzmann, J. Forster et al., "Linkage and allelic association of atopy and markers flanking the IL4receptor gene," Clinical and Experimental Allergy, vol. 28, no. 2, pp. 151-155, 1998.

[79] H. Mitsuyasu, K. Izuhara, X. Q. Mao et al., "Ile50Val variant of IL4R alpha upregulates IgE synthesis and associates with atopic asthma," Nature genetics, vol. 19, no. 2, pp. 119-120, 1998.

[80] L. Rosa-Rosa, N. Zimmermann, J. A. Bernstein, M. E. Rothenberg, and G. K. Khurana Hershey, "The R576 IL4 receptor allele correlates with asthma severity," Journal of Allergy and Clinical Immunology, vol. 104, no. 5, pp. 10081014, 1999.

[81] E. Noguchi, M. Shibasaki, T. Arinami et al., "No association between atopy/asthma and the Ile50Val polymorphism of IL4 receptor," American Journal of Respiratory and Critical Care Medicine, vol. 160, no. 1, pp. 342-345, 1999.

[82] H. Mitsuyasu, Y. Yanagihara, X. Q. Mao et al., "Cutting edge: dominant effect of Ile50Val variant of the human IL4 receptor $\alpha$-chain in IgE synthesis," Journal of Immunology, vol. 162, no. 3, pp. 1227-1231, 1999.

[83] K. A. Risma, N. Wang, R. P. Andrews et al., "V75R576 IL-4 receptor $\alpha$ is associated with allergic asthma and enhanced IL-4 receptor function," Journal of Immunology, vol. 169, no. 3, pp. 1604-1610, 2002.

[84] J. Brourad, N. Knauer, P.-Y. Boelle et al., "Influence of interleukin-10 on airways colonization by Aspergillus fumigatus in cystic fibrosis patients.," The Journal of Infectious Diseases, vol. 191, pp. 1988-1991, 2005.

[85] S. Saxena, T. Madan, A. Shah, K. Muralidhar, and P. U. Sarma, "Association of polymorphisms in the collagen region of SP-A2 with increased levels of total IgE antibodies and eosinophilia in patients with allergic bronchopulmonary 
aspergillosis," Journal of Allergy and Clinical Immunology, vol. 111, no. 5, pp. 1001-1007, 2003.

[86] L. F. Weikert, K. Edwards, Z. C. Chroneos, C. Hager, L. Hoffman, and V. L. Shepherd, "SP-A enhances uptake of bacillus Calmette-Guerin by macrophages through a specific SP-A receptor," American Journal of Physiology, vol. 272, no. 5, pp. L989-L995, 1997.

[87] P. W. Miller, A. Hamosh, M. Macek et al., "Cystic fibrosis transmembrane conductance regulator (CFTR) gene mutations in allergic bronchopulmonary aspergillosis," American Journal of Human Genetics, vol. 59, no. 1, pp. 45-51, 1996.

[88] J. E. Wang, A. Warris, E. A. Ellingsen et al., "Involvement of CD14 and Toll-like receptors in activation of human monocytes by Aspergillus fumigatus hyphae," Infection and Immunity, vol. 69, no. 4, pp. 2402-2406, 2001.

[89] S. Bellocchio, S. Moretti, K. Perruccio et al., "TLRs govern neutrophil activity in aspergillosis," Journal of Immunology, vol. 173, no. 12, pp. 7406-7415, 2004.

[90] R. Lazarus, W. T. Klimecki, B. A. Raby et al., "Singlenucleotide polymorphisms in the Toll-like receptor 9 gene (TLR9): frequencies, pairwise linkage disequilibrium, and haplotypes in three U.S. ethnic groups and exploratory casecontrol disease association studies," Genomics, vol. 81, no. 1, pp. 85-91, 2003.

[91] N. Novak, C. F. Yu, C. Bussmann et al., "Putative association of a TLR9 promoter polymorphism with atopic eczema," Allergy, vol. 62, no. 7, pp. 766-772, 2007.

[92] G. Gerold, K. A. Ajaj, M. Bienert, H. J. Laws, A. Zychlinsky, and J. L. de Diego, "A Toll-like receptor 2-integrin $\beta$ complex senses bacterial lipopeptides via vitronectin," Nature Immunology, vol. 9, no. 7, pp. 761-768, 2008.

[93] L. A. Weiss, L. A. Lester, J. E. Gern et al., "Variation in ITGB3 is associated with asthma and sensitization to mold allergen in four populations," American Journal of Respiratory and Critical Care Medicine, vol. 172, no. 1, pp. 67-73, 2005.

[94] I. M. J. Bromley and K. Donaldson, "Binding of Aspergillus fumigatus spores to lung epithelial cells and basement membrane proteins: relevance to the asthmatic lung," Thorax, vol. 51, no. 12, pp. 1203-1209, 1996.

[95] Y. Shibata, L. A. Foster, J. F. Bradfield, and Q. N. Myrvik, "Oral administration of chitin down-regulates serum IgE levels and lung eosinophilia in the allergic mouse," Journal of Immunology, vol. 164, no. 3, pp. 1314-1321, 2000.

[96] Z. Zhu, T. Zheng, R. J. Homer et al., "Acidic mammalian chitinase in asthmatic Th2 inflammation and IL-13 pathway activation," Science, vol. 304, no. 5677, pp. 1678-1682, 2004.

[97] R. Chatterjee, J. Batra, S. Das, S. K. Sharma, and B. Ghosh, "Genetic association of acidic mammalian chitinase with atopic asthma and serum total IgE levels," Journal of Allergy and Clinical Immunology, vol. 122, no. 1, pp. 202-208, 2008.

[98] C. Ober, Z. Tan, Y. Sun et al., "Effect of variation in CHI3L1 on serum YKL-40 level, risk of asthma, and lung function," New England Journal of Medicine, vol. 358, no. 16, pp. 16821691, 2008.

[99] N. E. Reijmerink, M. Kerkhof, G. H. Koppelman et al., "Smoke exposure interacts with ADAM33 polymorphisms in the development of lung function and hyperresponsiveness," Allergy, vol. 64, no. 6, pp. 898-904, 2009.

[100] H. Jongepier, H. M. Boezen, A. Dijkstra et al., "Polymorphisms of the ADAM33 gene are associated with accelerated lung function decline in asthma," Clinical and Experimental Allergy, vol. 34, no. 5, pp. 757-760, 2004.

[101] M. L. A. Schuttelaar, M. Kerkhof, M. F. Jonkman et al., "Filaggrin mutations in the onset of eczema, sensitization, asthma, hay fever and the interaction with cat exposure," Allergy, vol. 64, no. 12, pp. 1758-1765, 2009.

[102] G. H. Koppelman, D. A. Meyers, T. D. Howard et al., "Identification of PCDH1 as a novel susceptibility gene for bronchial hyperresponsiveness," American Journal of Respiratory and Critical Care Medicine, vol. 180, no. 10, pp. 929-935, 2009.

[103] S. J. Barton, G. H. Koppelman, J. M. Vonk et al., "PLAUR polymorphisms are associated with asthma, PLAUR levels, and lung function decline," Journal of Allergy and Clinical Immunology, vol. 123, no. 6, pp. 1391-1400, 2009.

[104] I. H. Heijink, D. S. Postma, J. A. Noordhoek, M. Broekema, and A. Kapus, "House dust mite-promoted epithelial-tomesenchymal transition in human bronchial epithelium," American Journal of Respiratory Cell and Molecular Biology, vol. 42, no. 1, pp. 69-79, 2010.

[105] P. A. B. Wark, M. J. Hensley, N. Saltos et al., "Antiinflammatory effect of itraconazole in stable allergic bronchopulmonary aspergillosis: a randomized controlled trial," Journal of Allergy and Clinical Immunology, vol. 111, no. 5, pp. 952-957, 2003.

[106] D. A. Stevens, H. J. Schwartz, J. Y. Lee et al., "A randomized trial of itraconazole in allergic bronchopulmonary aspergillosis," New England Journal of Medicine, vol. 342, no. 11, pp. 756-762, 2000. 


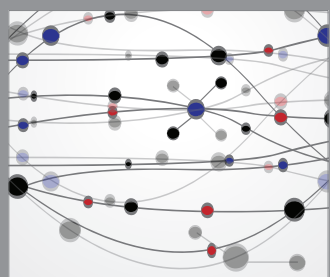

The Scientific World Journal
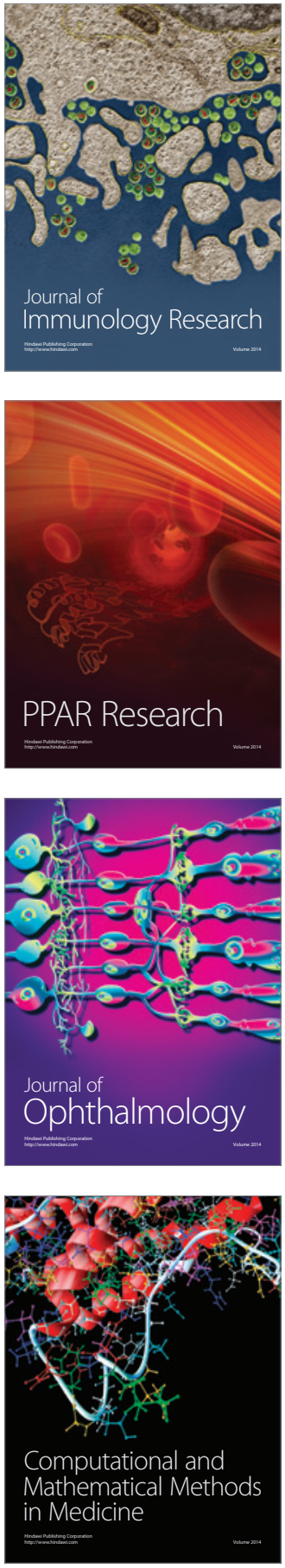

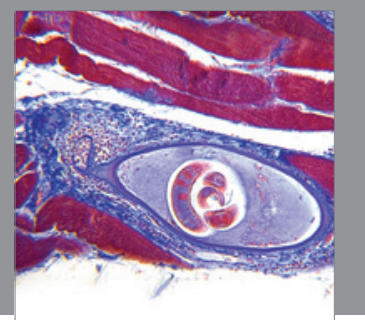

Gastroenterology

Research and Practice
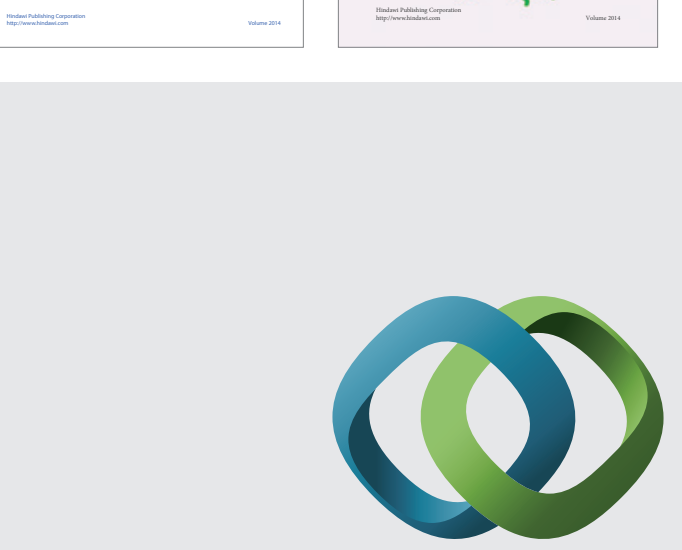

\section{Hindawi}

Submit your manuscripts at

http://www.hindawi.com
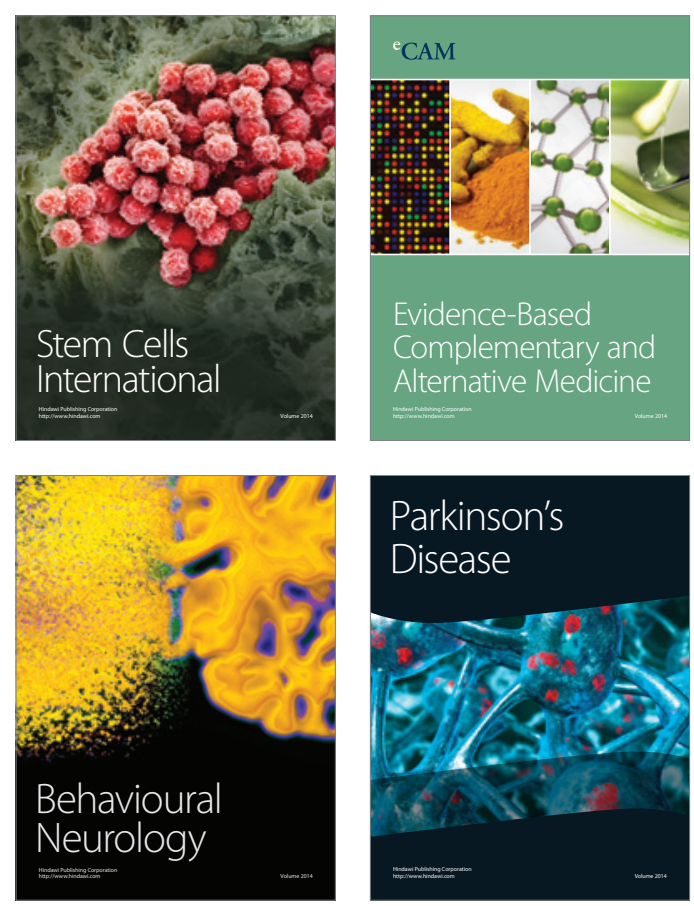

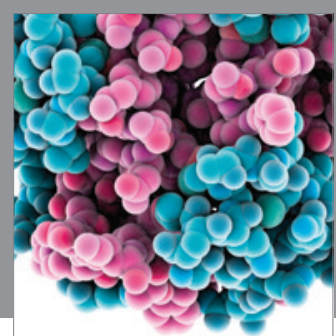

Journal of
Diabetes Research

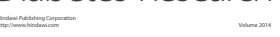

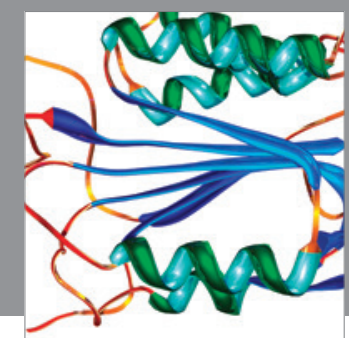

Disease Markers
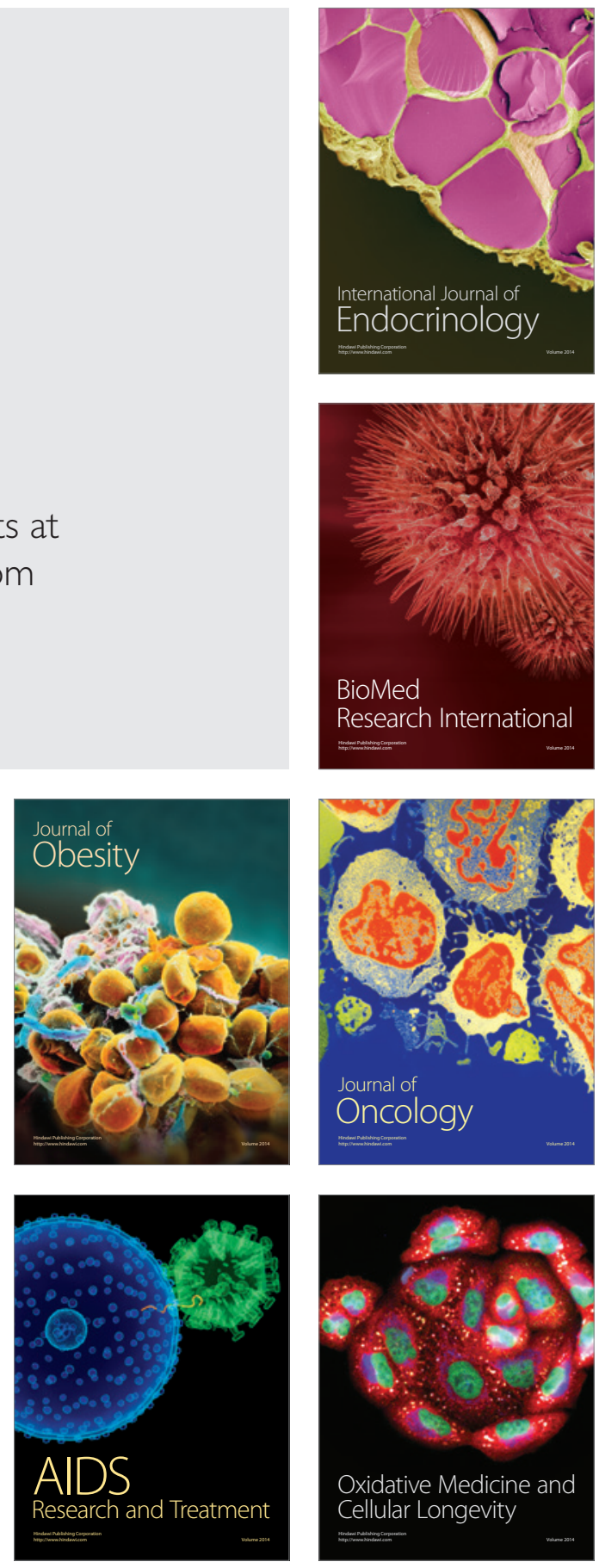